\title{
An Examination of the Present State of the Grimsby Trawl Fishery, with especial reference to the De- struction of Immature Fish.
}

\author{
By
}

\section{Ernest W. L. Holt.}

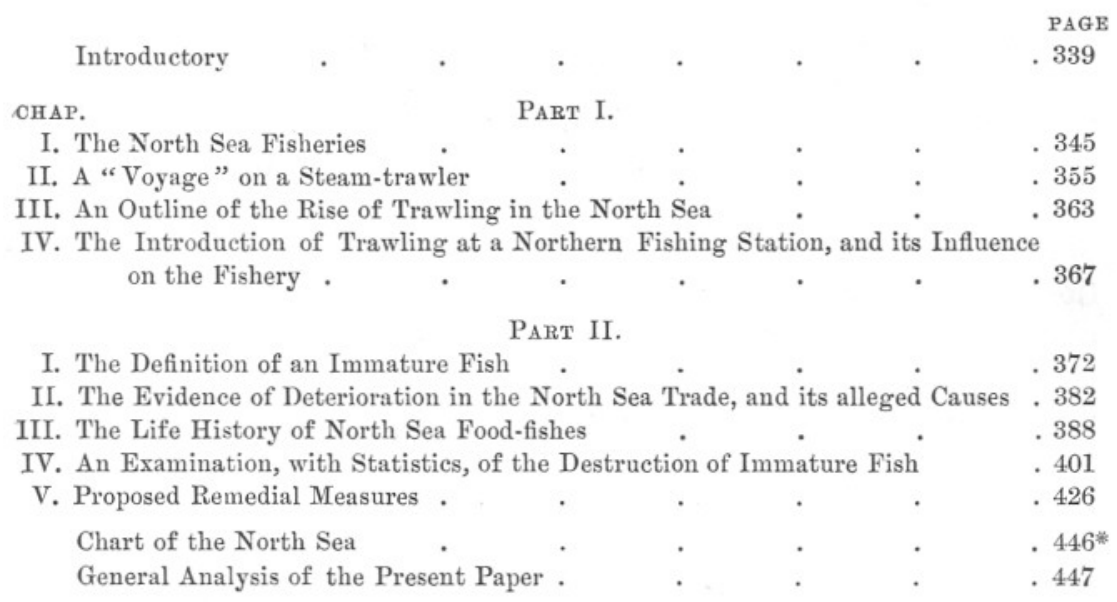

\section{INTRODUCTORY.}

IT will be within the recollection not only of the comparatively small section of the community which is consciously interested in fishery matters, but of all those whom a sense of public duty or a lack of other occupation compels to some acquaintance with the current topics of the day, that the question of the deterioration of our sea fisheries commenced some few years back to assume something approaching to prominence. One of the earlier indications of the importance with which the question was invested, in the minds of those principally concerned, was the formation, in 1882, by a number of fish merchants, smack-owners, and others, of the National Sea Fisheries Protection Association,-a title which may 
well be forgiven for its length, in consideration of the happy augury it holds out of the enduring nature of the Association's services to one of our most deserving industries.

The Association endeavoured to ascertain not only the extent of the evil with which it had set itself to battle, but also the best means of holding it in check, by adopting the method of summoning annual conferences, to which were invited fish merchants, smackowners, and fishermen from all parts of the coast, members of Parliament, and other guardians of the interests of the nation, and even representatives of such scientific bodies as endeavour to cultivate an acquaintance with matters marine. Subjects were selected for discussion and votes taken, which latter would perhaps have been more representative had not the power of voting been confined to members of the Association.

Every student of matters social is well aware that a Conference is usually prolific only to the third generation. It begets a Resolution, the offspring of which, adhering to the strictly discontinuous type of variation, is a Deputation. A deputation has been described as a "noun of multitude, which signifies many but does not signify much ;" and the unanimity with which the sufficiency of this definition is accepted by those in office, of whatever shade of politics, is alone sufficient to prove that " great minds think alike."

It is not surprising that the conferences with which we are dealing achieved, for several years, only the usual result, or want of it, since it cannot be expected that any parliament will lightly undertake legislation when the bulk of its members only profess such acquaintance with its subject as for once is actually somewhat akin to that which they possess; while, strange as it may possibly appear to less enlightened nations, the principal kingdom in the Union has no department capable of dealing with the matter by minor methods, though in Scotland there is a Fishery Board, and in Ireland a Fishery Office, entrusted with very considerable powers within the limits of their respective countries.*

The conferences, however, cannot be said to have been wholly without result, since in 1893 a Parliamentary Committee was appointed to hear evidence and furnish a report. On this report the hopes or fears of those interested are at present centred, according to the light in which they regard the recommendations it contains.

So far my remarks have only, and in the briefest possible manner, dealt with the attempts made by the N. S. F. P. Association, as representative of the fish trade, to induce the Government to take

* Somewhat similar powers are possessed by District Fisheries Committees of the County Councils in England, but each Council is independent of the others and, practically, of any central authority. 
steps to check the evil of which complaints were made, but other action was being taken in the meanwhile. The Marine Biological Association, although its activity is in the main directed to the prosecution of what would generally be termed strictly scientific pursuits, has always given prominence to the study of those organisms which are of importance to our fisheries. Thus, even before the Laboratory was completed, my colleague, Mr. Cunningham, had commenced his studies of the development and life-histories of the fishes which form the object of the fishing industry of Plymouth and the neighbouring coast-studies which have been continued without intermittence down to the present time. I allude only to those investigations which have a practical bearing such as appeals at once to the intelligence of every one, though it may be claimed with perfect truth that there is no item of marine biology that has not its economic importance directly or indirectly, in that due appreciation of the conditions of marine life without which no rational treatment of fishery questions can ever be attempted.

As may be supposed, the agitation in connection with the alleged deterioration of the fisheries came early under the notice of the Council. Complaints of the scarcity of fish, and of the injury inflicted by certain methods of fishing other than those used by plaintiffs, are matters of immemorial antiquity, but the present agitation was distinctly original in character. It had its origin, as usual, amongst those interested in one particular method of fishing, viz. trawling; but it differed from all other known fishery grievances in that the complaints of the trawlers, and of those who dealt in trawl-fish, were directed, not against some other body of fishermen, but against themselves.

The trawler, of course, has long been the recognised piscatorial scapegoat, reviled by the inshore line-fisherman with an energy which is usually in inverse ratio to that with which he pursues his own calling, and condemned with scant ceremony by the amateur "naturalist" and the public at large. But on this occasion, as I have said, the trawler was his own accuser, and it must be noted that the agitation originated with, and was practically confined to, the ports of Grimsby and Hull, the two greatest trawling centres of the North Sea, which is, of course, by far the most important trawling district. Other trawling communities, if aware that they were doing excessive damage, at all events did not consider that the remedy lay beyond their own powers.

An agitation conducted by one class against another obviously invites the suspicion that it is based chiefly on motives of selfinterest, without any particular regard for the welfare of the community at large; but in a case like the present, though self-interest 
may reasonably be inferred to be the motive of inception, there would seem to be a much greater chance than usual that the object desired is for the general benefit as well as for that of the agitators.

Still, however strongly the genuine nature of an agitation may appear to be warranted by the probabilities of the case, common prudence demands that it should be supported by the most exact evidence of which the circumstances permit; and especially is this the case in fishery affairs, since experience has taught us that the ignorance of the fisherman of the most elementary features in the natural history of the organisms on which he depends, often leads him to set forth as fact, matter which is by no means capable of that denomination.

Moreover, granted that the complaints prove to be well founded, it will be conceded that remedial measures beneficial to the whole community have their best chance of origin in investigations conducted from a standpoint altogether independent of any trade interest whatsoever.

On these accounts it appeared to the Council of the Marine Biological Association that here was an investigation in which the means at the disposal of the Association could be most usefully employed, and no time was lost in instituting a series of inquiries as to the alleged destruction of immature fish by beam-trawling in the North Sea, and the best means of checking such destruction, if it should be found to exist on a serious scale.

These inquiries the Council was good enough to place in my charge, and for three years, according to my ability and opportunities, I have laboured to collect whatever information seemed to bear on the case. My headquarters were at Grimsby, where the Association, by arrangement with a local Society, secured a small laboratory, fitted with tanks and other conveniences, for my use. From time to time I have communicated the result of my inquiries, either in the form of articles in the Association's Journal, reports to the Council, or evidence before the Parliamentary Committee.

At the end of three years the object of the investigations may be said to have been accomplished, since sufficient evidence has been collected to allow us to form a fairly reliable opinion on the question, and the investigations have accordingly been closed so far as this particular matter is concerned.

Of course an important fishery like that of the North Sea will always afford abundant scope for the activity of the scientific inquirer, but no new question of paramount importance has as yet arisen, nor, indeed, is the old one by any means settled. Still we have at our disposal all the material necessary for dealing with it in a rational way, should such a proceeding ever commend itself to our 
legislators. I have indicated the various channels through which my information and views have already been communicated to the public; and, on closing the inquiries, I have been requested by the Council to draw up a brief epitome of the results arrived at, so that they may be presented to the public in a concrete form.

To do this is the object of the present paper, which is designed for a section of the public much more extensive than that which is in the habit of concerning itself with the literature of professional fishery. It is too much to hope that I may be able to invest my remarks with any interest not indissolubly connected with the subject itself, since facts are at best dry reading, and the habits of the scientific writer are not such as to pre-eminently qualify him for the lighter graces of popular penmanship.

A few words are necessary as to the arrangement of my material. The complaints of the trawlers and fish merchants resolved themselves into the following brief statement:-That large numbers of immature fish were destroyed by trawling, and that the supply of trawl-fish in the North Sea was in consequence diminishing. The fish especially referred to were flat-fish, the question of round-fish being considered of secondary importance. It was evident that, as to the diminution of the supply, I could not hope to obtain any absolute evidence of my own. Whatever information was deducible from the Board of Trade statistics was open to every one, and those statistics hardly went far enough back to be of much value, and were, and are, altogether insufficient in detail. I had, therefore, to depend, in forming an opinion, entirely on the reminiscences of fishermen, eked out in a few cases by the books of smack-owners. Any details of information under the last heading I am neither at liberty nor in the position to publish, and I must dismiss this branch of the inquiry with the assertion, whatever it may be worth, that I hold the opinion that there has been a considerable deterioration in the supply of the more valuable kinds of flat-fish. In the case of haddocks I am not convinced that the deterioration has been considerable. Such statistical work as I have carried on since I went to Grimsby will be referred to in due course.

With regard to the alleged destruction of immature fish, the first point to ascertain was the correct definition of the term immature ; and then to find out where, and to what extent, the alleged destruction took place. This involved an examination of the different grounds, with the collection of all possible information as to their previous history.

Inseparably related to the whole question is the condition of the 
trawl-fishery as a whole, the methods by which it is conducted, and the conditions of the trawlers' life. Not only the deep-sea fisheries, but all minor industries which could in any way affect the question, demanded inquiry, and in the succeeding chapters I shall endeavour to deal with these several matters. 